\title{
Improved Photoelectrochemical Performance of Bismuth Vanadate by Partial O/F-Substitution
}

\author{
B. Anke, ${ }^{a, 1}$ M. Rohloff, ${ }^{a, b, 1}$ M.G. Willinger, ${ }^{c}$ W. Hetaba,${ }^{c, d}$ A. Fischer,${ }^{* b}$ M. Lerch ${ }^{* a}$ \\ ${ }^{a}$ Institut für Chemie, Technische Universität Berlin, Straße des 17. Juni 135, 10623 Berlin \\ ${ }^{\mathrm{b}}$ Institut für Anorganische und Analytische Chemie, Albert-Ludwigs-Universität Freiburg, Albertstraße 21, \\ 79104 Freiburg \\ ${ }^{c}$ Department of Inorganic Chemistry, Fritz Haber Institute of the Max Planck Society, Faradayweg 4-6, 14195 \\ Berlin \\ ${ }^{\mathrm{d}}$ Department of Heterogeneous Reactions, Max-Planck-Institute for Chemical Energy Conversion, Stiftstraße \\ 34-36, 45470 Mülheim an der Ruhr \\ ${ }^{1}$ These authors contributed equally to the research
}

\section{Keywords}

$\mathrm{BiVO}_{4} ; \mathrm{O} / \mathrm{F}$-substitution; crystal structure; optical properties; water oxidation; photoelectrochemical water splitting

\begin{abstract}
Fluorine-containing bismuth vanadate $\left(\mathrm{F}: \mathrm{BiVO}_{4}\right)$ powder was synthesized using a new, clean, and simple solid-vapor reaction. Incorporation of fluorine mainly leads to the formation of cation vacancies. Electrodes were fabricated from the pre-synthesized powder samples by electrophoretic deposition onto fluorine-doped tin oxide coated glass slides and subsequent calcination. The photoelectrochemical performance concerning the water oxidation reaction was investigated and compared to pristine $\mathrm{BiVO}_{4}$ revealing strongly enhanced photoelectrochemical behavior for the F-containing $\mathrm{BiVO}_{4}$.
\end{abstract}

\section{Introduction}

In the past years a lot of attention was paid to the semiconductor bismuth vanadate $\mathrm{BiVO}_{4}$, because of its outstanding catalytic properties. Since Kudo et al.[1] discovered $\mathrm{BiVO}_{4}$ to be a photoactive material it is not only used as brilliant, non-toxic yellow pigment[2,3] but also as catalyst for the photodegradation of organic pollutants.[4-7] Today, most attention is paid to the use of $\mathrm{BiVO}_{4}$ as photoanode material for water splitting under visible-light irradiation.[8] 
There are many parameters influencing the photoelectrochemical performance of semiconductors with respect to water splitting.[9] For instance, the crystal structure of a semiconductor material like $\mathrm{BiVO}_{4}$ is a very important factor to be considered. At ambient pressure $\mathrm{BiVO}_{4}$ exhibits three important polymorphs crystallizing either in the scheelite-type structure (monoclinic, tetragonal) or in the tetragonal zirkon-type structure. Among these three polymorphs, the monoclinic phase shows the highest activity for water oxidation: a result which is ascribed to the smaller band gap of the monoclinic phase $(2.4 \mathrm{eV})$ compared to the one of tetragonal zircon-type structure $(3.1 \mathrm{eV})$.[10]

Another way to influence the photoelectrochemical behavior of a semiconductor is to change its electronic structure by, for example, partial cation substitution. Molybdenum and tungsten were found to be suitable cationic dopants improving the photoelectrochemical properties due to enhancement of the amount of free charge carriers within the $\mathrm{BiVO}_{4}$ material.[11-17] Besides cationic doping, also anion substitution, especially with fluorine, seems to lead to a decrease of the optical band gap resulting in an increase of photoelectrochemical performance. $[4,18]$ However such materials have not been studied in detail so far.

One possible route to fluorine incorporation into oxides involves polyvinylidene fluoride (PVDF) as fluoride source and was reported by Slater.[19] Following Slaters method, the reactants must be mixed, which in terms of photo(electro-)catalytic performance might represent a big disadvantage because of potential carbon contamination of the final product. With this in mind, we developed a new process for the synthesis of F-containing $\mathrm{BiVO}_{4}$ $\left(\mathrm{F}: \mathrm{BiVO}_{4}\right)$ based on a solid-vapor reaction with separated reactants at ambient pressure and in inert gas atmosphere. Using electrophoretic deposition and taking advantage of the lowtemperature sintering of $\mathrm{BiVO}_{4}$, the as-synthesized powders could be processed to $\mathrm{F}: \mathrm{BiVO}_{4}$ photoanodes, with highly improved PEC performance when compared to their pristine counterparts (vide infra). 


\section{Experimental Section}

\subsection{Synthesis}

$\mathrm{BiVO}_{4}$ was synthesized in an aqueous medium at room temperature under ambient pressure. $7.29 \mathrm{~g} \mathrm{Bi}_{2} \mathrm{O}_{3}\left(99.9 \%\right.$ Aldrich) and $3.81 \mathrm{~g} \mathrm{NaVO}_{3}$ (98\% AlfaAesar) were dissolved in concentrated $\mathrm{HNO}_{3}$. After mixing these solutions, $\mathrm{NaOH}$ was added until the $\mathrm{pH}$ value reached basic conditions $(\mathrm{pH}=12)$. The solution was stirred for $4 \mathrm{~h}$. The resultant yellow precipitate was washed with distilled water several times to remove impurities and unreacted precursor materials, filtered, and dried at $60{ }^{\circ} \mathrm{C}$ for $12 \mathrm{~h}$.

F-containing $\mathrm{BiVO}_{4}$ was prepared by a solid-vapor reaction using an indirect gas flow apparatus (see Figure 1). Loose powder of pure $\mathrm{BiVO}_{4}$ was loaded in a small corundum boat, which in turn was placed inside a larger corundum boat containing varying amounts of PVDF. This arrangement advantageously prevents contact between the reagents in either solid or liquid form. The nested boats were then placed inside a corundum tube with one closed end and then placed in a horizontal tube furnace with a low nitrogen gas flow of $5 \mathrm{l} / \mathrm{h}$. The temperature was set to $380{ }^{\circ} \mathrm{C}$ for 24 hours and after a final heating step in air at $450{ }^{\circ} \mathrm{C}$ for 30 minutes an orange powder was obtained. Thermogravimetric and mass spectroscopy studies revealed that the PVDF decomposition only emits HF under inert gas. Before electrode preparation the pristine $\mathrm{BiVO}_{4}$ was also tempered at $450{ }^{\circ} \mathrm{C}$ to imitate the final heating step of F-containing $\mathrm{BiVO}_{4}$.

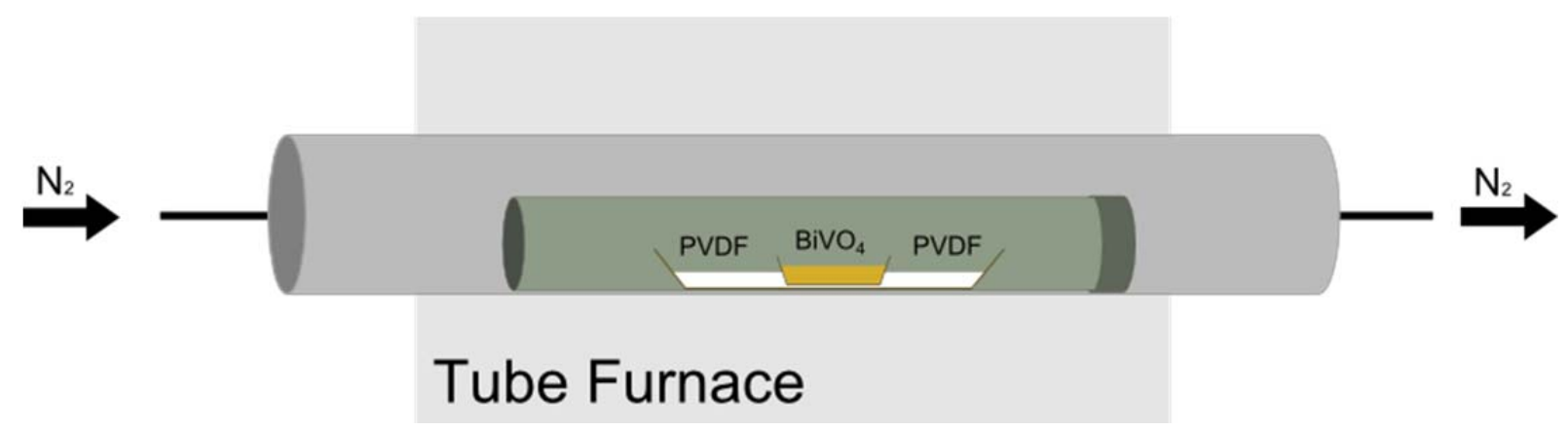

Figure 1. Sketch of fluorination apparatus. The inner corundum boat contains the sample to be fluorinated and the outer boat is filled with PVDF. 


\subsection{Chemical and structural characterization}

The products were characterized by X-ray powder diffraction using a PANalytical X'Pert PRO diffractometer (Bragg-Brentano geometry, $\mathrm{Cu}-\mathrm{K} \alpha$ radiation). All structural refinements were performed with the program FullProf Suite Version 2009 by applying a pseudo-Voigt function.[20] The oxygen content was determined by hot gas extraction method (LECO TC$300 / \mathrm{EF}-300$ ). For calibration, $\mathrm{ZrO}_{2}$ was used as standard material. The accuracy is $\sim 2 \%$ of the presented $\mathrm{O}$ content. For ICP-OES investigations, $5 \mathrm{mg} \mathrm{BiVO}_{4}$ powder was dissolved in $10 \mathrm{ml}$ water containing $3.5 \mathrm{vol} \% \mathrm{HCl}$. Measurements were carried out using a Varian ICPOES 715 ES with radial plasma torch. For SEM investigations of fabricated electrodes, a Hitachi SU8030 operated at an acceleration voltage of $10 \mathrm{kV}$ was used. Experimental density values of the samples were measured using a Quantachrome helium multipycnometer, where the pressure change of helium in a calibrated volume is measured to calculate the sample volume. Helium penetrates into smallest pores and crevices and permits to approach the real volume of the sample. Transmission electron microscopy (TEM) and energy dispersive X-ray (EDX) analysis were performed using a FEI Talos F200X equipped with a SuperX EDX system, incorporating four Bruker silicon drift detectors (SDD).

\subsection{UV-vis spectroscopy}

Diffuse reflectance spectra were collected with a Jasco V670 spectrometer using $\mathrm{MgO}$ as white standard. Absorbance spectra were calculated from the measured diffuse reflectance with the Kubelka-Munk function: $(R)=\frac{(1-R)^{2}}{2 R}=\varepsilon \mathrm{c} \frac{1}{\mathrm{~s}}$,

where $R$ is the reflectance, $\varepsilon$ is the absorption coefficient, $c$ the concentration of absorbing species, and $s$ the scattering coefficient. The optical band gap was determined using the modified Tauc equation, $[F(R) h v]^{\frac{1}{n}}=A\left(h v-E_{g}\right)$, with $F(R)$ the Kubelka-Munk function, $h v$ the photon energy, $E_{g}$ the optical band gap, and $A$ a proportionality constant.[21,22] The value of the exponent $n$ denotes the nature of the transition. A direct allowed transition is present in $\mathrm{BiVO}_{4}: n=1 / 2 .[23,24]$

\subsection{Electrode Fabrication}

An electrophoretic deposition method (EPD) based on a procedure Domen et al. reported was used to fabricate electrodes for photoelectrochemical investigations.[25] In a first step, the pristine as well as the F-containing powder was treated for $15 \mathrm{~min}$ in a mixer mill (Retsch $\mathrm{GmbH}$ MM301) to provide a comparable particle size distribution (verified by SEM- 
investigations). $80 \mathrm{mg}$ of the respective $\mathrm{BiVO}_{4}$ powder was dispersed in $50 \mathrm{ml}$ iodinecontaining acetone $\left(2 \mathrm{mg} \mathrm{I}_{2} / \mathrm{ml}\right.$ acetone) by extended ultrasonification $(27 \mathrm{kHz})$ at room temperature. Two fluorine-doped tin oxide coated glass slides (FTO) were immersed parallel in the dispersion with $1.0 \mathrm{~cm}$ of distance. Particles were deposited by application of a potential of $10 \mathrm{~V}$ for $5 \mathrm{~min}$. This procedure was repeated twice in total. After electrophoretic deposition, the as-prepared electrodes were calcined at $450{ }^{\circ} \mathrm{C}$ for $30 \mathrm{~min}$ under air. Additionally, electrodes were also calcined at $550{ }^{\circ} \mathrm{C}$ for $30 \mathrm{~min}$ under air to improve PEC performance by enhanced sintering of the electrode particles (see SI).

In order to ensure that the fluorine content of the material did not change during the described procedures, hot gas extraction measurements were carried out after the milling step, as well as after the heat treatment steps at $450{ }^{\circ} \mathrm{C}$ and $550{ }^{\circ} \mathrm{C}$ for 30 minutes, respectively. The determined oxygen contents are the same $(18.2 \mathrm{wt} \%)$ for all samples; a result which is a clear indication for the good thermal stability of the fluorine-containing material.

\subsection{Electrochemical Investigations}

Photoelectrochemical (PEC) measurements were carried out in a 3-electrode-setup consisting of the $\mathrm{BiVO}_{4}$ - working electrode, a Pt-wire counter electrode, and a reversible hydrogen reference electrode. The potential of the working electrode was controlled by a potentiostat (Biologic SP-150). Electrodes were illuminated by a $150 \mathrm{~W}$ Xe-lamp at a spectral range of 400-700 $\mathrm{nm}$. The light intensity at the electrode surface was adjusted to $100 \mathrm{~mW} / \mathrm{cm}^{2}$ using a Si-diode light meter. If not stated otherwise, backside illumination (i.e. illumination via the FTO-coated glass side of the $\mathrm{BiVO}_{4}$ photoanode) was used.

A photo-assisted electrodeposition method based on the procedure reported by Durrant et al. was used to deposit a cobalt phosphate based water oxidation catalyst (CoPi) onto the $\mathrm{F}: \mathrm{BiVO}_{4}$ electrode surface.[26] The working electrode was immersed in $0.1 \mathrm{M}$ potassium phosphate buffer at $\mathrm{pH} 7.3$ containing $0.5 \mathrm{mM}$ cobalt nitrate and a constant potential of $1.2 \mathrm{~V}$ vs. RHE was applied under illumination. To ensure a comparable amount of deposited CoPi for all samples, the deposition was stopped after a charge of $130 \mathrm{mC}$ was flown.

All $\mathrm{j}-\mathrm{V}$-measurements were conducted in a $0.1 \mathrm{M}$ potassium phosphate (KPi) buffer at $\mathrm{pH} 7.3$ using a scan rate of $20 \mathrm{mV} / \mathrm{s}$. For chronoamperometric measurements of the photocurrent transients a potential of $1.23 \mathrm{~V}$ vs. RHE was applied and blue light $(440 \mathrm{~nm})$ at an intensity of $1 \mathrm{~mW} / \mathrm{cm}^{2}$ was used. Staircase potentio-electrochemical impedance spectroscopy (PEIS, Mott-Schottky Analysis) was carried out in $0.5 \mathrm{M} \mathrm{KPi}$ buffer at $\mathrm{pH} 7.3$ scanning from anodic 
to cathodic potentials and using a sinusoidal modulation of $10 \mathrm{mV}$ at frequencies of $500 \mathrm{~Hz}$ and $1 \mathrm{kHz}$.[27] An area of $0.5 \mathrm{~cm}^{2}$ of each electrode was used for measurements.

\section{Results and discussion}

\subsection{Chemical analysis and crystal structure}

We successfully synthesized orange-colored $\mathrm{F}: \mathrm{BiVO}_{4}$ as phase-pure material. ICP-OES analysis showed a $\mathrm{Bi}: \mathrm{V}$ ratio of $0.999: 1$. Quantitative chemical analysis by hot gas extraction was used to measure the amount of oxygen. In the case of pristine $\mathrm{BiVO}_{4}$ the experimental value of $19.7 \mathrm{wt} \%$ is identical with the theoretical one. As an expected result of fluorine incorporation, a slightly lower value $(18.2 \mathrm{wt} \%)$ was obtained for $\mathrm{F}: \mathrm{BiVO}_{4}$.

Figure 2 (left) depicts a bright-field transmission electron microscopy (TEM) overview image of the fluorine-containing sample while on the right side a high-resolution TEM (HRTEM) image can be seen. From the right micrograph, the crystalline structure of the particles is evident. Fast-Fourier-transformation (FFT) of this region shows the spatial frequencies due to the lattice fringes, which can be assigned to the monoclinic $\mathrm{BiVO}_{4}$ structure.
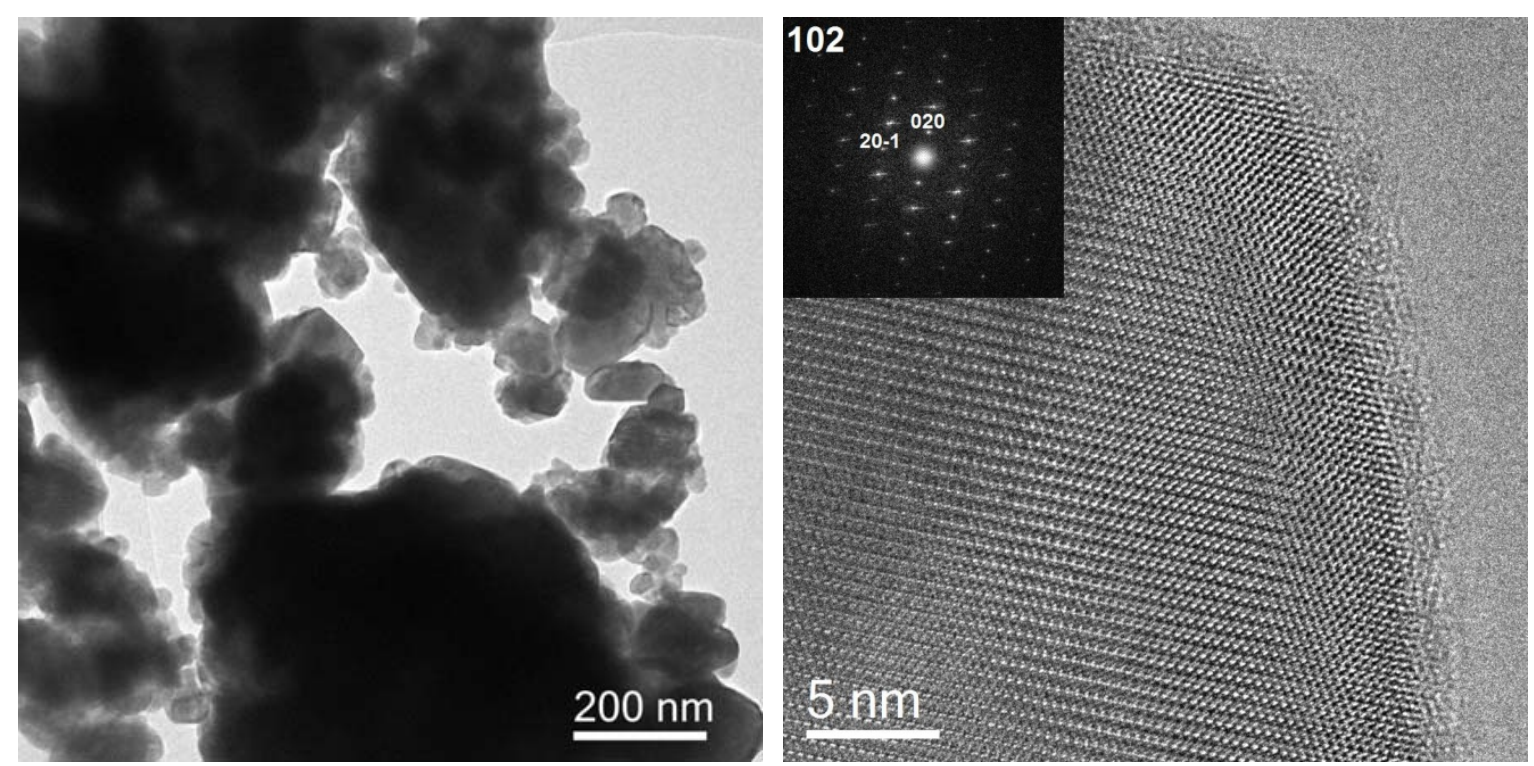

Figure 2. Bright field TEM image of $\mathrm{F}: \mathrm{BiVO}_{4}$ (left) and high resolution TEM image of one of the particles (right). The inlay shows the corresponding FFT. Spots due to the (020) and (20-1) lattice planes or the [102] oriented particle are labelled. 


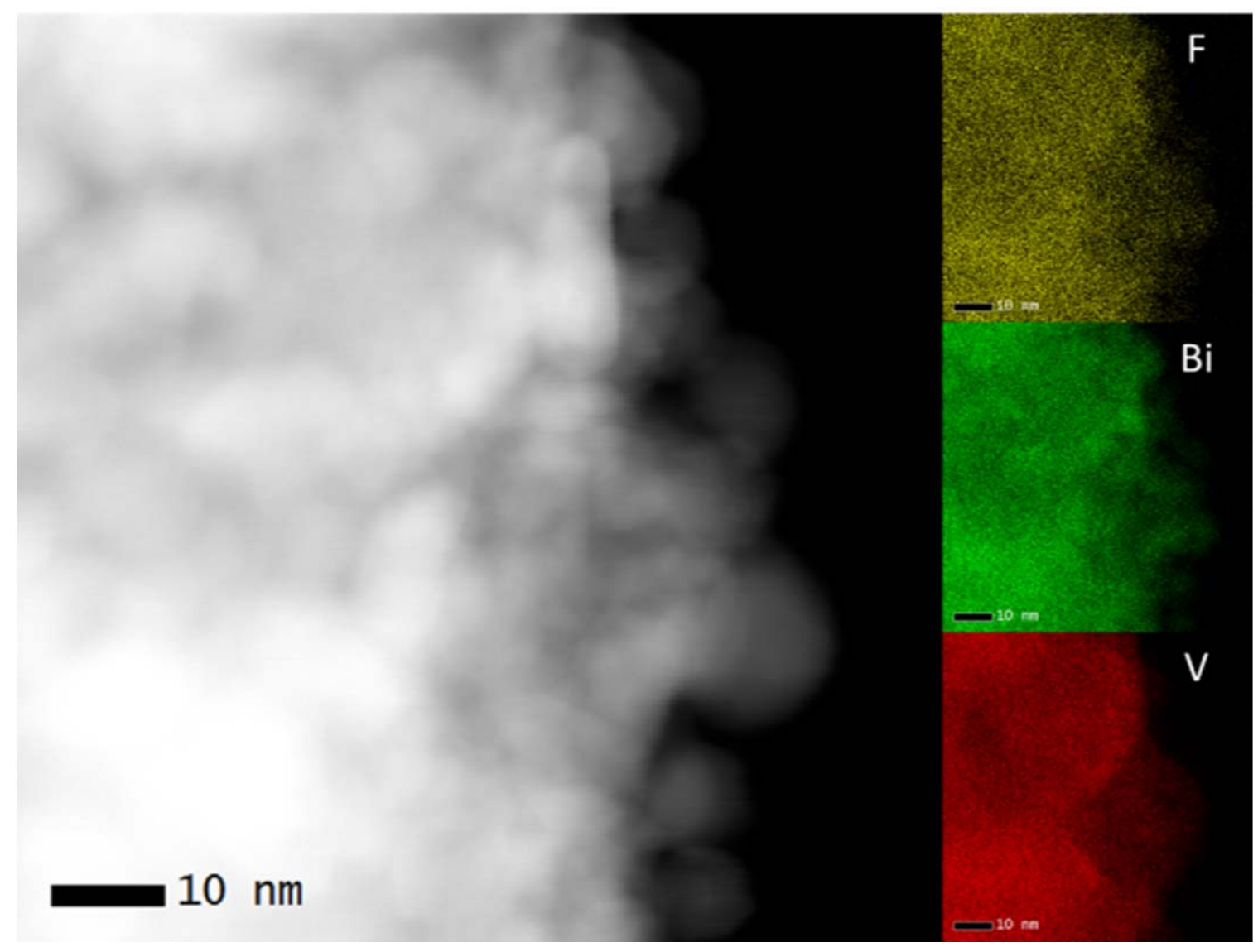

Figure 3. High angle annular dark field image of $\mathrm{F}: \mathrm{BiVO}_{4}$ (left). EDX maps of $\mathrm{F}$ (yellow), $\mathrm{Bi}$ (green) and V(red) (right from top to bottom).

Figure 3 presents a high angle annular dark field (HAADF) overview image with the corresponding EDX maps of F (yellow), Bi (green) and V (red), revealing a homogeneous distribution of these elements in the material. The oxygen content could not be abstracted by EDX. Due to the limited energy resolution of the EDX detector $(\sim 126 \mathrm{eV})$ the oxygen $\mathrm{K}$ (around $530 \mathrm{eV}$ ) and vanadium L (around $518 \mathrm{eV}$ ) ionization edges overlap to a single peak and cannot be distinguished. The vanadium content was quantified using the vanadium Kedge. Elemental quantification by EDX performed in the SEM and TEM at different magnifications confirmed a homogeneous distribution of fluorine in the material. According to the quantification, the samples contain equal amounts of Bi and $\mathrm{V}$.

The structural refinements of $\mathrm{BiVO}_{4}$ and $\mathrm{F}: \mathrm{BiVO}_{4}$ were started from the coordinates reported for the clinobisvanite structure of monoclinic $\mathrm{BiVO}_{4}$ (space group I2/b (No. 15), JCPDS 140688).[28] The results clearly demonstrate that fluorine incorporation does not change the structure type. Further details of the crystal structure investigation(s) may be obtained from the Fachinformationszentrum Karlsruhe, D-76344 Eggenstein-Leopoldshafen (Germany), on quoting the depository number CSD-431572. Figure 4 depicts the X-ray powder diffraction 
patterns of pristine (left) and $\mathrm{F}$ containing (right) $\mathrm{BiVO}_{4}$ along with the results of the Rietveld refinements. Final structural parameters are listed in Table 1.
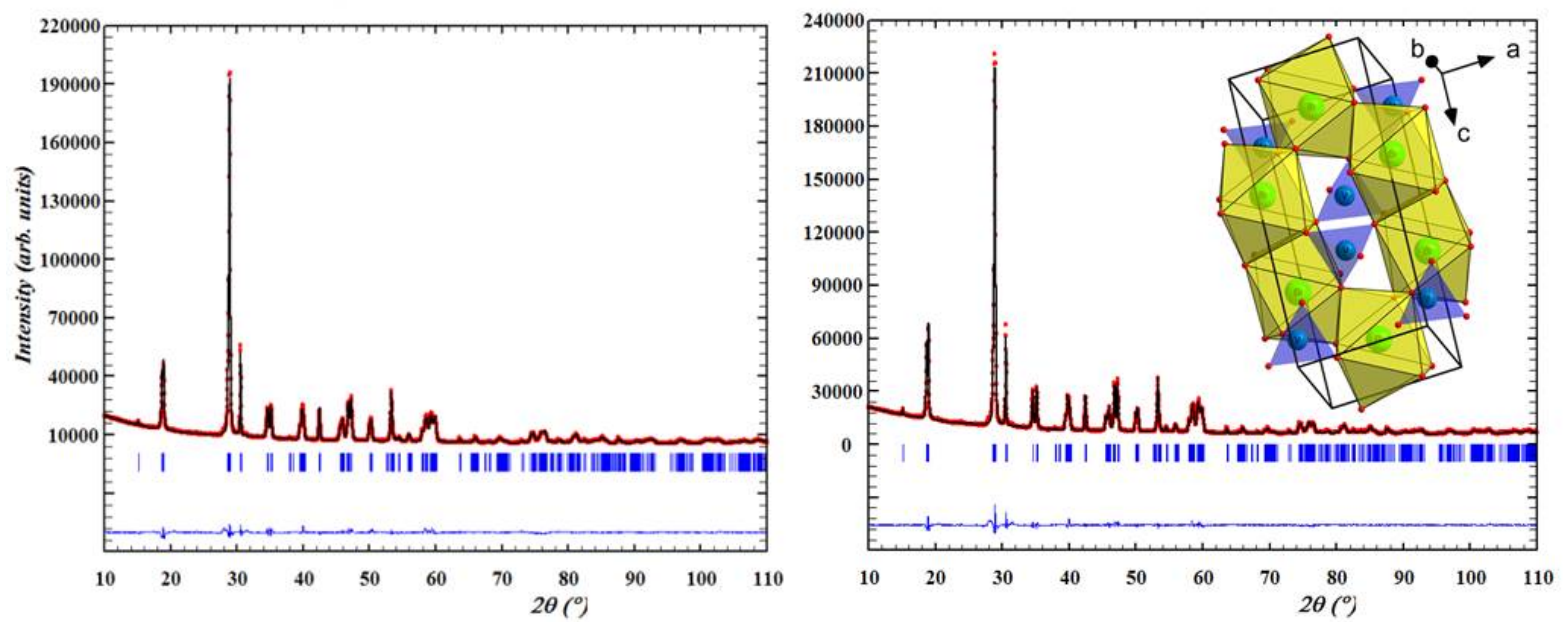

Figure 4. X-ray powder diffraction patterns of $\mathrm{BiVO}_{4}$ (left) and $\mathrm{F}: \mathrm{BiVO}_{4}$ (right) with the results of the Rietveld refinements. Inset: Unit cell of $\mathrm{F}: \mathrm{BiVO}_{4}$ and polyhedral representation of the crystal structure. $\mathrm{Bi}(\mathrm{O}, \mathrm{F})_{8}$ polyhedra are drawn in yellow, $\mathrm{V}(\mathrm{O}, \mathrm{F})_{4}$ tetraheda are shown in blue.

Table 1a. Refined structural parameters of $\mathrm{BiVO}_{4}$ in comparison to $\mathrm{F}: \mathrm{BiVO}_{4}$.

\begin{tabular}{|c|c|c|}
\hline Composition & $\mathrm{BiVO}_{4}$ & $\mathrm{~F}: \mathrm{BiVO}_{4}$ \\
\hline Crystal system & \multicolumn{2}{|c|}{ monoclinic } \\
\hline Space group & \multicolumn{2}{|c|}{$I 2 / b($ No. 15$)$} \\
\hline Formular units & \multicolumn{2}{|c|}{$Z=4$} \\
\hline \multirow{4}{*}{ Lattice parameters } & $a=5.1787(5) \AA$ & $a=5.1863(4) \AA$ \\
\hline & $b=5.1042(5) \AA$ & $b=5.1003(4) \AA$ \\
\hline & $c=11.6953(11) \AA$ & $c=11.6998(8) \AA$ \\
\hline & $\gamma=90.260(2)^{\circ}$ & $\gamma=90.3082(12)^{\circ}$ \\
\hline Unit cell volume & $V=309.16(5) \AA^{3}$ & $V=309.47(5) \AA^{3}$ \\
\hline Calc. density & $6.962 \mathrm{~g} / \mathrm{cm}^{3}$ & $\begin{array}{l}\text { See discussion of the } \\
\text { defect models below }\end{array}$ \\
\hline Meas. density & $6.89(2) \mathrm{g} / \mathrm{cm}^{3}$ & $6.68(2) \mathrm{g} / \mathrm{cm}^{3}$ \\
\hline $\mathrm{R}_{\mathrm{wp}}$ & 0.0300 & 0.0358 \\
\hline $\mathrm{R}_{\text {Bragg }}$ & 0.0301 & 0.0421 \\
\hline $\mathrm{R}_{\exp }$ & 0.0101 & 0.0097 \\
\hline S & 2.97 & 3.69 \\
\hline
\end{tabular}


Table 1b: Structural parameters for $\mathrm{BiVO}_{4}$ and $\mathrm{F}: \mathrm{BiVO}_{4}$.

\begin{tabular}{|ccccccc|}
\hline $\mathrm{BiVO}_{4}$ & Wyckoff & $x$ & $y$ & $z$ & $\mathrm{~B}_{\text {iso }}$ & s.o.f. \\
$\mathrm{Bi}$ & $4 e$ & 0 & $1 / 4$ & $0.63277(10)$ & 0.9 & $0.960(4)$ \\
$\mathrm{V}$ & $4 e$ & 0 & $1 / 4$ & $0.1297(4)$ & 0.6 & $1.014(4)$ \\
$\mathrm{O} 1$ & $8 f$ & $0.1349(18)$ & $0.4906(15)$ & $0.2061(8)$ & 1.2 & 1 \\
$\mathrm{O} 2$ & $8 f$ & $0.2680(13)$ & $0.3729(18)$ & $0.4477(8)$ & 1.2 & 1 \\
$\mathrm{~F}: \mathrm{BiVO}$ & Wyckoff & $x$ & $y$ & $z$ & $\mathrm{~B}_{\text {iso }}$ & s.o.f. \\
$\mathrm{Bi}$ & $4 e$ & 0 & $1 / 4$ & $0.63283(10)$ & 0.9 & $0.930(6)$ \\
$\mathrm{V}$ & $4 e$ & 0 & $1 / 4$ & $0.1302(4)$ & 0.6 & $0.922(6)$ \\
$\mathrm{O} 1$ & $8 f$ & $0.1444(18)$ & $0.4969(14)$ & $0.2082(8)$ & 1.2 & 1 \\
$\mathrm{O} 2$ & $8 f$ & $0.2733(51)$ & $0.3765(18)$ & $0.4438(7)$ & 1.2 & 1 \\
\hline
\end{tabular}

The Debye-Waller factors were not refined and set identically for both phases. Whereas the lattice parameters show some significant change, the positional parameters are very similar. The resulting bond lengths for $\mathrm{BiVO}_{4}$ and $\mathrm{F}: \mathrm{BiVO}_{4}$ are given in the SI. The values can be described as more or less identical with no systematic trend. The refined site occupation factors are most interesting. For pristine bismuth vanadate a small but significant underoccupation for bismuth and an overoccupation for vanadium are observed. In contrast, severe underoccupations for both cations were the result of the best refinement of the Fcontaining material. Being aware of systematic problems such as strong correlations between atomic displacement parameters and site occupation factors, and after testing various models in respect of possible defect structures, these results may give us a hint to the correct defect model for fluorine incorporation into $\mathrm{BiVO}_{4}$, which will be discussed below. Finally, it should be stated that, unfortunately, the elements oxygen and fluorine cannot be distinguished using $\mathrm{X}$-ray or even neutron diffraction methods. Because both anion positions are coordinated by three cations, Paulings second rule cannot be used to predict a preferred position for fluorine, as it has also been generally described in the work by Fuertes.[29]

For a deeper understanding of the fluorine-containing material a closer look at possible mechanisms of fluorine incorporation is helpful. In principle, there are three different sensible defect models according to which fluorine incorporation can take place: a) formation of cation vacancies; b) fluorine on interstitial sites, and c) partial reduction of vanadium. For the following explanations we use the notation of Kröger and Vink.[30]

a) Formation of cation (vanadium and bismuth) vacancies is described by 
$\mathrm{Bi}_{\mathrm{Bi}}^{\mathrm{x}}+\mathrm{V}_{\mathrm{V}}^{\mathrm{X}}+8 \mathrm{O}_{\mathrm{O}}^{\mathrm{x}}+8 \mathrm{HF}=\mathrm{V}_{\mathrm{Bi}}^{\prime \prime \prime}+\mathrm{V}_{\mathrm{V}}^{\prime \prime \prime \prime \prime}+8 \mathrm{~F}_{\mathrm{O}}^{\bullet}+\mathrm{BiVO}_{4}(\mathrm{sf})+4 \mathrm{H}_{2} \mathrm{O}$

Taking into consideration the experimentally determined oxygen content of $18.2 \mathrm{wt} \%$, a chemical formula of $\mathrm{Bi}_{0.94} \mathrm{~V}_{0.94} \mathrm{O}_{3.54} \mathrm{~F}_{0.46}$ can be calculated. The corresponding theoretical density (taken the volume from the Rietveld refinement) would account for $6.66 \mathrm{~g} / \mathrm{cm}^{3}$.

b) Fluorine incorporation on interstitial sites is described by

$\mathrm{O}_{\mathrm{O}}^{\mathrm{x}}+2 \mathrm{HF}=\mathrm{F}_{\mathrm{O}}^{\bullet}+\mathrm{F}_{\mathrm{i}}^{\prime}+\mathrm{H}_{2} \mathrm{O}$

leading to a chemical formula of $\mathrm{BiVO}_{3.75} \mathrm{~F}_{0.50}$ and a theoretical density of $7.07 \mathrm{~g} / \mathrm{cm}^{3}$.

c) Partial reduction of vanadium from formal valence state V to IV can be described using the following equation:

$2 \mathrm{~V}_{\mathrm{V}}^{\mathrm{x}}+2 \mathrm{O}_{\mathrm{O}}^{\mathrm{x}}+2 \mathrm{HF}=2 \mathrm{~V}_{\mathrm{V}}^{\prime}+2 \mathrm{~F}_{\mathrm{O}}^{\bullet}+\mathrm{H}_{2} \mathrm{O}+\frac{1}{2} \mathrm{O}_{2}$

resulting in a chemical formula of $\mathrm{BiV}_{0,70}^{\mathrm{V}} \mathrm{V}^{\mathrm{IV}}{ }_{0,30} \mathrm{O}_{3,70} \mathrm{~F}_{0,30}$ and a theoretical density of $6.97 \mathrm{~g} / \mathrm{cm}^{3}$.

In order to identify the correct defect model following considerations need to be discussed:

- The experimentally determined density of $6.68(2) \mathrm{g} / \mathrm{cm}^{3}$ for the F-containing material clearly points to the presence of cation vacancies (expected value $6.66 \mathrm{~g} / \mathrm{cm}^{3}$; note that for the other models the density is larger compared to that of fluorine-free $\mathrm{BiVO}_{4}$ with a value of $\left.6.96 \mathrm{~g} / \mathrm{cm}^{3}\right)$.

- The presence of cation vacancies (model a) is supported by the strong underoccupation of the cation positions, as determined from the Rietveld refinement. In addition, the calculated chemical composition of $\mathrm{Bi}_{0.94} \mathrm{~V}_{0.94} \mathrm{O}_{3.54} \mathrm{~F}_{0.46}$ is in good agreement with the composition coming from the refined site occupation factors $\left(\mathrm{Bi}_{0.93} \mathrm{~V}_{0.92}(\mathrm{O}, \mathrm{F})_{4}\right)$. It should be mentioned that an alternative refinement strategy with fully occupied atomic positions and refined Debye-Waller factors for oxygen (approximated anion interstitial model) led to clearly poorer results (e. g. increase of the Bragg R-factor from $4.2 \%$ (vacancy model) to 4.9 (interstitial model).

- The occupation of anion interstitials by fluorine (model b, $\mathrm{BiV}(\mathrm{O}, \mathrm{F})_{4.25}$ ) seems to be not very reasonable from a crystal chemistry point of view. Such a large amount of interstitial ions should strongly decrease the stability of the crystal structure.

- Due to the fact that the samples are very beam sensitive, estimations of the oxidation state on the basis of electron energy-loss spectrometry were not possible. Nevertheless, taking into account the refined cation occupation factors, the measured density, and the observed orange 
color (the color of such a large amount of reduced vanadium - see calculated chemical formula - is expected to be black), model $\mathrm{c}$, the reduction of vanadium, can be ruled out.

Taking into consideration the previous results, there are strong indications for the presence of cation vacancies as majority defect in fluorine-containing bismuth vanadate. From now on, we mean $\mathrm{Bi}_{0.94} \mathrm{~V}_{0.94} \mathrm{O}_{3.54} \mathrm{~F}_{0.46}$ when discussing $\mathrm{F}: \mathrm{BiVO}_{4}$. It should be mentioned that large concentrations of cation vacancies are also reported for other $\mathrm{BiVO}_{4}$-based phases. For example, partial substitution of $\mathrm{V}^{5+}$ by $\mathrm{Mo}^{6+}$ leads to the formation of phases of the $\mathrm{Bi}_{1-\mathrm{x} / 3} \mathrm{Mo}_{\mathrm{x}} \mathrm{V}_{1-\mathrm{x}} \mathrm{O}_{4}$ type. [31]

\subsection{Optical properties}

Optical absorbance of a semiconductor plays an important role for the photelectrochemical behavior.[32] Orange-colored $\mathrm{F}: \mathrm{BiVO}_{4}$ and yellow-colored $\mathrm{BiVO}_{4}$ were measured in diffuse reflectance geometry. The results were converted to Tauc plots in order to estimate the optical band gap by extrapolating tangents to the x-axis as shown in Figure 5. For F:BiVO ${ }_{4}$ the optical band gap is reduced to $2.38 \mathrm{eV}$ in comparison to the measured pristine $\mathrm{BiVO}_{4}$ with a band gap of $2.45 \mathrm{eV}$. This band-gap reduction, also found in the contributions of Jiang et al.[4] and Li et al.,[18] is beneficial in terms of light absorption (shift of the absorption edge from 500 to $520 \mathrm{~nm}$ upon fluorine incorporation).

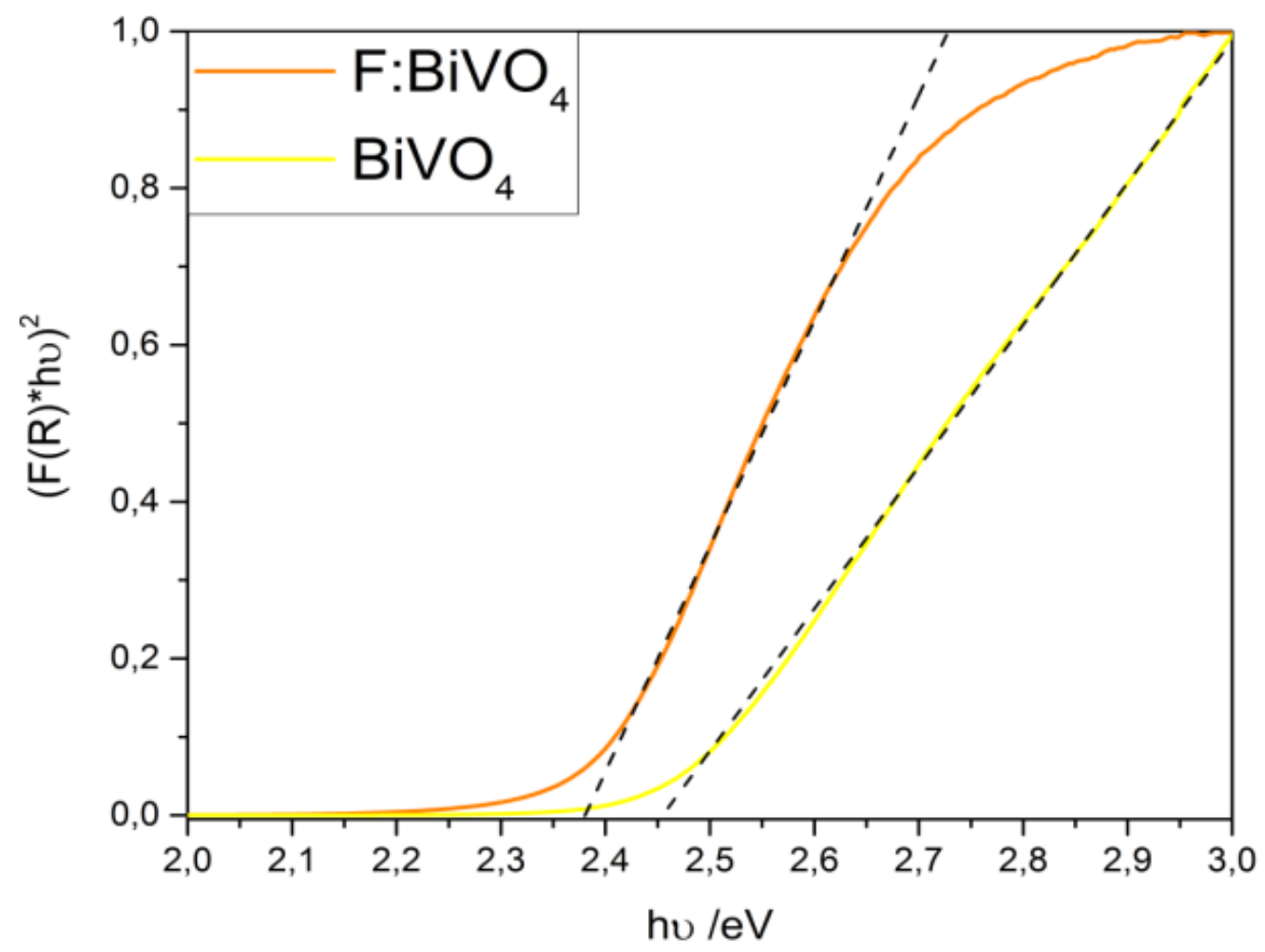

Figure 5: Tauc plot for $\mathrm{BiVO}_{4}$ and $\mathrm{F}: \mathrm{BiVO}_{4}$ based on diffuse reflectance spectrometry. 


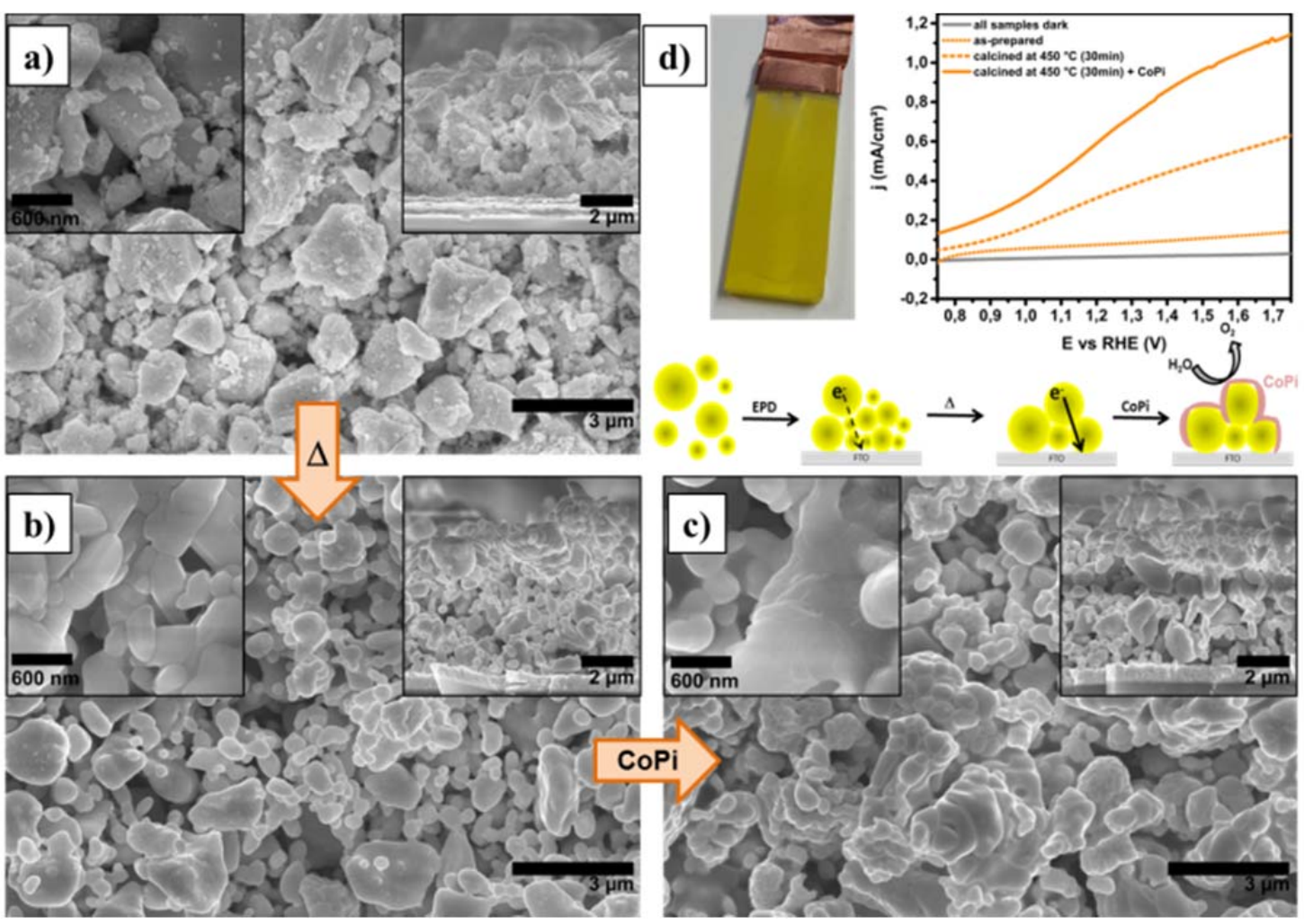

Figure 6: Illustration of electrode fabrication process: SEM top-view and cross-sectional images of a) as-prepared electrodes, b) calcined electrodes $\left(450^{\circ} \mathrm{C}\right.$ under air), c) calcined electrodes with deposited CoPi co-catalyst layer, d) Picture of an $\mathrm{F}: \mathrm{BiVO}_{4}$ electrode and j-V-curves: as-prepared $\mathrm{F}: \mathrm{BiVO}_{4}$, calcined $\mathrm{F}: \mathrm{BiVO}_{4}$ and $\mathrm{F}: \mathrm{BiVO}_{4}$ with a deposited CoPi layer $(0.1$ M KPi buffer, $\mathrm{pH} 7.3,20 \mathrm{mV} / \mathrm{s}$ ).

\subsection{Electrochemical investigations}

To investigate the photocatalytic properties, photoanodes were fabricated out of the presynthesized powders by electrophoretic deposition on FTO-coated glass slides. To achieve a good interparticle percolation within the deposited $\mathrm{F}: \mathrm{BiVO}_{4}$ films, a calcination step at higher temperature was performed after deposition. The respective electrode fabrication steps were thereby followed by scanning electron microscopy (top-view and cross-section) (Figure 6, see SI for SEM data of the respective samples calcined at $550{ }^{\circ} \mathrm{C}$ ). As-prepared electrodes consist of a loosely packed particle layer of $\sim 5 \mu \mathrm{m}$ thickness which homogeneously spreads over the entire FTO substrate as shown in Figure 6a. Calcination under air (at $450{ }^{\circ} \mathrm{C}$ and $550{ }^{\circ} \mathrm{C}$ ) causes sintering of the deposited particles to a denser layer of $\mathrm{F}: \mathrm{BiVO}_{4}($ Figure $\mathbf{6 b}$ ), creating a continuously connected particle network. As shown in Figure 6c after co-catalyst deposition the sintered particles are covered by a thin layer of CoPi (see SI for corresponding EDX spectra). Sintering of the particles improves ohmic contact within the film and is therefore beneficial for the overall electric conductivity and photoelectrochemical behavior, respectively. As shown in Figure 6d the photocurrent for the as-prepared F:BiVO 4 electrode 
is rather low (ca. $0.05 \mathrm{~mA} / \mathrm{cm}^{2}$ at $1.23 \mathrm{~V}$ vs. RHE) but can significantly be enhanced (x 6) by calcination of the electrode at $450{ }^{\circ} \mathrm{C}$ for 30 minutes $\left(0.3 \mathrm{~mA} / \mathrm{cm}^{2}\right.$ at $1.23 \mathrm{~V}$ vs. RHE). Increasing the calcination temperature to $550{ }^{\circ} \mathrm{C}$ further improved the PEC performance, leading to a further increase ( $\mathrm{x} 2$ ) of the photocurrents at $1.23 \mathrm{~V}$ vs $\operatorname{RHE}\left(0.6 \mathrm{~mA} / \mathrm{cm}^{2}\right)$. Additional deposition of a layer of $\mathrm{CoPi}$ on the respective photoanodes improves in both cases $\left(450{ }^{\circ} \mathrm{C}\right.$ and $550^{\circ} \mathrm{C}$ ) the PEC performance by improving the water oxidation kinetics, reaching photocurrents as high as $0.64 \mathrm{~mA} / \mathrm{cm}^{2}$ and $1.23 \mathrm{~mA} / \mathrm{cm}^{2}$ at $1.23 \mathrm{~V}$ vs. RHE for the $450{ }^{\circ} \mathrm{C}$ and $550{ }^{\circ} \mathrm{C}$ treated electrodes respectively.

The effect of fluorine incorporation on the performance of $\mathrm{BiVO}_{4}$ concerning photoelectrochemical water oxidation was investigated by comparing the performance of $\mathrm{F}: \mathrm{BiVO}_{4}$ with pristine $\mathrm{BiVO}_{4}$ photoanodes prepared under the same conditions and with comparable amounts of deposited powder ( $3.5 \mathrm{mg}$ per electrode).

Figure 7a and $\mathbf{b}$ display the $\mathrm{j}-\mathrm{V}$-curves of both $\mathrm{BiVO}_{4}$ and $\mathrm{F}: \mathrm{BiVO}_{4}$ electrodes calcined at $450{ }^{\circ} \mathrm{C}$ and $550^{\circ} \mathrm{C}$ prior and after $\mathrm{CoPi}$ deposition. In all cases, a significant increase in photocurrent is observed for the F-containing electrodes; effect which most probably relates to the improved light-absorption of the system (see UV-Vis data, vide supra). Note: In all cases the water oxidation photocurrents are low compared to the highest reported photocurrent values for $\mathrm{BiVO}_{4}$ photoanodes (about $4 \mathrm{~mA} / \mathrm{cm}^{2}$ at $1.23 \mathrm{~V}$ vs RHE)[33-35] but are fully in line with photocurrents achieved for EPD-processed $\mathrm{BiVO}_{4}$-electrodes (about $\left.0.6 \mathrm{~mA} / \mathrm{cm}^{2}\right) \cdot[36,37]$

In order to understand the improvement of the photoelectrochemical performance, photocurrent transient measurements (Figure 7c and d) were carried out for both materials and both calcination temperatures. When the light was switched on, the pristine $\mathrm{BiVO}_{4}$ electrode $\left(450{ }^{\circ} \mathrm{C}\right)$ showed a photocurrent overshoot followed by a fast decrease of the photocurrent. In contrast, the photocurrent decay observed for $\mathrm{F}: \mathrm{BiVO}_{4}$ was far less pronounced; indication for a decreased recombination rate within the F-modified system. The main limiting factor for $\mathrm{BiVO}_{4}$ as anode material for water splitting was elucidated in previous reports to be its poor bulk electronic conductivity.[38] Despite possible negative effects on charge carrier mobility and diffusion length, doping allows in general increasing the charge carrier density and therefore allows enhancement of the overall photoresponse. Consistently, F-containing $\mathrm{BiVO}_{4}$ showed a by far less pronounced decrease of photocurrent after the light was switched on (i.e. a slower recombination of light-induced charge carrier) leading to a better photoresponse and higher photocurrents of the F-modified system. 
To further clarify the origin of improved photocatalytic properties of $\mathrm{F}: \mathrm{BiVO}_{4}$ Mott-Schottkytype potentio-electrochemical impedance spectroscopy measurements for both materials were performed. This method relies on measuring the capacitance of the space charge region $C_{S C}$ at the semiconductor electrolyte interface. According to the Mott-Schottky equation the flat band potential $E_{F B}$ and the carrier concentration $N$ can be calculated by the linear region of the plot of $1 / C_{S C}{ }^{2}$ versus applied potential $\mathrm{E}$ as indicated in the following equation:

$\frac{1}{C_{S C}^{2}}=\frac{2}{\varepsilon_{0} \varepsilon_{r} A^{2} e N}\left(E-E_{F B}-\frac{k_{b} T}{e}\right)$.

$\varepsilon_{r}$ thereby stands for the relative permittivity of the semiconductor, $\varepsilon_{0}$ the permittivity in vacuum, $A$ the surface area of the electrode, $e$ the charge of an electron, $k_{b}$ the Boltzmann constant and $T$ the temperature.
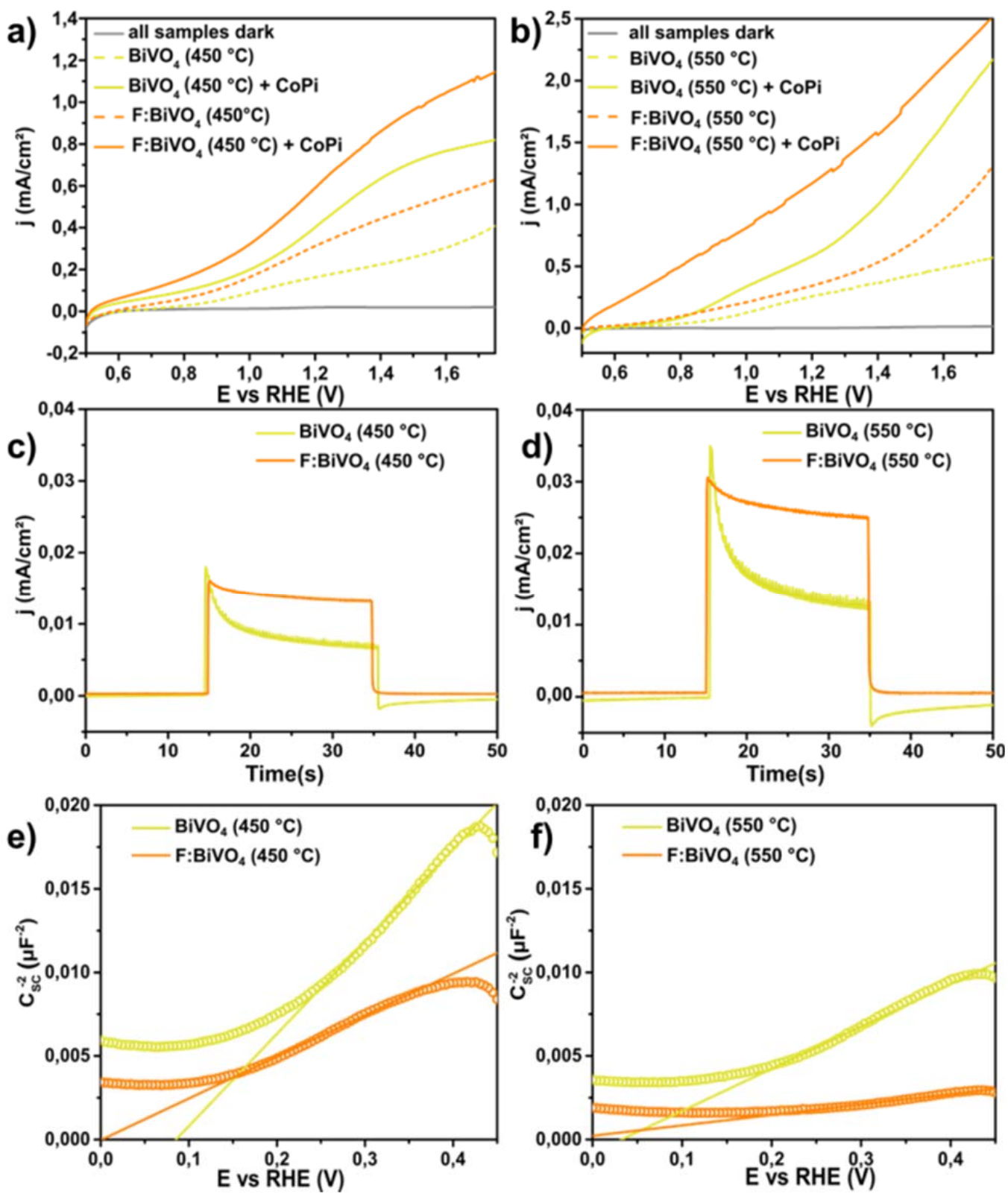
Figure 7: Electrochemical investigations of $\mathrm{BiVO}_{4}$ and $\mathrm{F}: \mathrm{BiVO}_{4}$ electrodes calcined at $450{ }^{\circ} \mathrm{C}$ and $550{ }^{\circ} \mathrm{C}$ : a and b) $\mathrm{j}-\mathrm{V}$ curves, c and d) phototransient measurements, light on/off at $\mathrm{E}=1.23 \mathrm{~V}$ and e and f) Mott-Schottky-Plots of $\mathrm{BiVO}_{4}$ and $\mathrm{F}: \mathrm{BiVO}_{4}$ at $1 \mathrm{kHz}$.

Due to the particulate morphology of the electrodes, it was uncertain whether Mott-Schottky analysis would provide convincing results. However as illustrated in Figure 7e and $\mathbf{f}$ the obtained values for $E_{F B}$ are in line with previously published $E_{F B}$ values for $\mathrm{BiVO}_{4} \cdot[7,12,35,39]$ For the pristine $\mathrm{BiVO}_{4}$ flatband potentials of $0.06 \mathrm{~V}$ vs. RHE for the $450{ }^{\circ} \mathrm{C}$ sample and of $0.03 \mathrm{~V}$ vs. RHE for the $550{ }^{\circ} \mathrm{C}$ sample were obtained. The $\mathrm{E}_{\mathrm{FB}}$ of $\mathrm{F}: \mathrm{BiVO}_{4}$ was determined to be slightly more negative at $-0.03 \mathrm{~V}$ vs. RHE for electrodes calcined at $450{ }^{\circ} \mathrm{C}$ and at $-0.06 \mathrm{~V}$ for the $550{ }^{\circ} \mathrm{C}$ sample. Our results show a negative shift of the flat band potential of about $0.1 \mathrm{~V}$ for $\mathrm{F}: \mathrm{BiVO}_{4}$ for both calcination temperatures. Furthermore, a comparison of the slopes of the linear ranges of the Mott-Schottky plots reveals a much smaller slope for $\mathrm{F}: \mathrm{BiVO}_{4}$ and hence - taken the surface area of the electrode as constant into account, as a result of comparable particle sizes, identical amount of deposited powder and same electrolyte exposed electrode area of $0.5 \mathrm{~cm}^{2}$ (see SI) - a higher carrier concentration. As such, these findings are in good agreement with our results on the light-induced water oxidation properties of pristine and F-containing $\mathrm{BiVO}_{4}$.

\section{Conclusion}

In here a simple route to phase pure fluorine modified $\mathrm{BiVO}_{4}$ is reported $\left(\mathrm{F}: \mathrm{BiVO}_{4}\right)$. Incorporation of fluorine into $\mathrm{BiVO}_{4}$ results in the formation of cation vacancies leading to the formation of $\mathrm{Bi}_{0.94} \mathrm{~V}_{0.94} \mathrm{O}_{3.54} \mathrm{~F}_{0.46}$. Investigations of the photoelectrochemical behavior show that F-incorporation significantly improves the performance of $\mathrm{BiVO}_{4}$ photoanodes for PEC water oxidation. Mott-Schottky analysis and photocurrent transient measurements further indicate a favorable displacement of the flat-band potential and an increase of charge carrier density as well as a substantial suppression of charge-carrier recombination in the fluorine modified system, respectively: improvements, which results in higher PEC performance. As such, fluorine incorporation into $\mathrm{BiVO}_{4}$ turns out to be an effective way to optimize its performance for PEC water oxidation and might be in general a promising strategy to further tune the photo(electro-)catalytic activity of other oxide based photoactive materials. 


\section{Acknowledgments}

The authors would like to thank S. Kühn (TU Berlin) for performing UV/Vis measurements and A. Müller-Klauke (TU Berlin) for performing ICP-OES investigations. The authors would like to thank the ZELMI (TU Berlin) and in particular Ulrich Gernet for access to and support with SEM measurements. This work is supported by the Deutsche Forschungsgemeinschaft (DFG) within the priority program SPP 1613 (LE 781/13-2, FI $1885 / 1-2)$ as well as by the DFG cluster of Excellence UniCat.

\section{References}

[1] A. Kudo, K. Ueda, H. Kato, I. Mikami, Catal. Lett. 53 (1998) 229-230.

[2] M. C. Neves, M. Lehocky, R. Soares, L. Lapcik, T. Trindade, Dyes Pigm. 59 (2003) 181-184.

[3] M. Gotić, S. Musić, M. Ivanda, M. Šoufek, S. Popović, J. Mol. Struct. $744-747$ (2005) 535-540.

[4] H. Jiang, H. Dai, J. Deng, Y. Liu, L. Zhang, K. Ji, Solid State Sci. 17 (2013) 21-27.

[5] C. Karunakaran, S. Kalaivani, Mater. Sci. Semicond. Process. 27 (2014) 352-361.

[6] M.J. Nalbandian, M. Zhang, J. Sanchez, Y.-H. Choa, D.M. Cwiertny, N.V. Myung, J. Mol. Catal. A: Chem. 404-405 (2015) 18-26.

[7] M. Zhou, J. Bao, W. Bi, Y. Zeng, R. Zhu, M. Tao, Y. Xie, ChemSusChem 5 (2012) $1420-1425$.

[8] Y. Park, K.J. McDonald, K.-S. Choi, Chem. Soc. Rev. 42 (2013) 2321-2337.

[9] M.G. Walter, E.L. Warren, J.R. McKone, S.W. Boettcher, Q. Mi, E.A. Santori, N.S. Lewis, Chem. Rev. 110 (2010) 6446-6473.

[10] S. Tokunaga, H. Kato, A. Kudo, Chem. Mater. 13 (2001) 4624-4628.

[11] K.P.S. Parmar, H.J. Kang, A. Bist, P. Dua, J.S. Jang, J.S. Lee, ChemSusChem 5 (2012) 1926-1934.

[12] H.S. Park, K.E. Kweon, H. Ye, E. Paek, G.S. Hwang, A.J. Bard, J. Phys. Chem. C 115 (2011) 17870-17879.

[13] S.P. Berglund, A.J.E. Rettie, S. Hoang, C.B. Mullins, Phys. Chem. Chem. Phys. 14 (2012) 7065-7075.

[14] H.W. Jeong, T.H. Jeon, J.S. Jang, W. Choi, H. Park, J. Phys. Chem. C 117 (2013) 91049112.

[15] S.K. Pilli, T.E. Furtak, L.D. Brown, T.G. Deutsch, J.A. Turner, A.M. Herring, Energy Environ. Sci. 4 (2011) 5028.

[16] W. Yao, H. Iwai, J. Ye, Dalton Trans. (2008) 1426-1430.

[17] F.F. Abdi, N. Firet, R. van de Krol, ChemCatChem 5 (2013) 490-496.

[18] J.-Q. Li, Z.-Y. Guo, H. Liu, J. Du, Z.-F. Zhu, J. Alloys Comp. 581 (2013) 40-45.

[19] P.R. Slater, J. Fluor. Chem. 117 (2002) 43-45.

[20] J. Rodriguez-Carvajal, Physica B 55 (1993) 192.

[21] J. Tauc, Mat. Res. Bull. 3 (1968) 37-46.

[22] Y. Izumi, T. Itoi, S. Peng, K. Oka, Y. Shibata, J. Phys. Chem. C 113 (2009) 6706-6718.

[23] A. Walsh, Y. Yan, M.N. Huda, M.M. Al-Jassim, S.-H. Wei, Chem. Mater. 21 (2009) 547-551.

[24] M.W. Stoltzfus, P.M. Woodward, R. Seshadri, J.-H. Klepeis, B. Bursten, Inorg. Chem. 46 (2007) 3839-3850. 
[25] R. Abe, M. Higashi, K. Domen, J. Am. Chem. Soc. 132 (2010) 11828-11829.

[26] Y. Ma, F. Le Formal, A. Kafizas, S.R. Pendlebury, J.R. Durrant, J. Mater. Chem. A 3 (2015) 20649-20657.

[27] Z. Chen, H.N. Dinh, E. Miller, Photoelectrochemical Water Splitting, Springer New York, New York, NY, 2013.

[28] A.W. Sleight, H.-y. Chen, A. Ferretti, D.E. Cox, Mat. Res. Bull. 14 (1979) 1571-1581.

[29] A. Fuertes, Inorg. Chem. 45 (2006) 9640-9642.

[30] F.A. Kröger, H.J. Vink, in: Sammelwerk Kröger-Vink, Elsevier, 1956, pp. 307-435.

[31] M. Cesari, G. Perego, A. Zazzetta, G. Manara, B. Notari, J. Inorg. Nucl. Chem. 33(10) (1971) 3595-3597.

[32] K. Lai, Y. Zhu, J. Lu, Y. Dai, B. Huang, Solid State Sci. 24 (2013) 79-84.

[33] T.W. Kim, K.-S. Choi, Science (New York, N.Y.) 343 (2014) 990-994.

[34] M. Zhong, T. Hisatomi, Y. Kuang, J. Zhao, M. Liu, A. Iwase, Q. Jia, H. Nishiyama, T. Minegishi, M. Nakabayashi, N. Shibata, R. Niishiro, C. Katayama, H. Shibano, M. Katayama, A. Kudo, T. Yamada, K. Domen, J. Am. Chem. Soc. 137 (2015) 5053-5060.

[35] F.F. Abdi, L. Han, A.H.M. Smets, M. Zeman, B. Dam, R. van de Krol, Nat. Commun. 4 (2013) 2195.

[36] D. Wang, R. Li, J. Zhu, J. Shi, J. Han, X. Zong, C. Li, J. Phys. Chem. C 116 (2012) 5082-5089.

[37] W.J. Jo, J.-W. Jang, K.-j. Kong, H.J. Kang, J.Y. Kim, H. Jun, K.P.S. Parmar, J.S. Lee, Angew. Chem. Int. Ed. Engl. 51 (2012) 3147-3151.

[38] F.F. Abdi, T.J. Savenije, M.M. May, B. Dam, R. van de Krol, J. Phys. Chem. Lett. 4 (2013) 2752-2757.

[39] A.J.E. Rettie, H.C. Lee, L.G. Marshall, J.-F. Lin, C. Capan, J. Lindemuth, J.S. McCloy, J. Zhou, A.J. Bard, C.B. Mullins, J. Am. Chem. Soc. 135 (2013) 11389-11396. 